\title{
Research Impact Evaluation Tools: Myths and Reality
}

\author{
Dr Bhupesh Rawat ${ }^{1}$, Dr Ankur Singh Bist ${ }^{2}$, Giandari Maulani ${ }^{3}$, Nur Azizah $^{4}$, \\ Fitra Putri Oganda ${ }^{5}$
}

Faculty of Computer Applications ${ }^{1}$, Faculty of Computer Science and Engineering ${ }^{2}$, Faculty of Information System ${ }^{3,4}$, Faculty of Science and Technology 5

Graphic Era Hill University ${ }^{1,2}$, University of Raharja ${ }^{3,4,5}$

Road Society Area, Oghal Bhatta, Clement Town, Dehradun, Uttarakhand $248002^{1,2}$

Jl. Jenderal Sudirman No.40, RT.002/RW.006, Cikokol, Kec. Tangerang, Kota Tangerang, Banten $15117^{3,4,5}$

e-mail: bhr222@gmail.com ${ }^{1}$, ankur1990bist@gmail.com ${ }^{2}$, giandari@raharia.info ${ }^{3}$, nur.azizah@raharia.info ${ }^{4}$, fitra.putri@raharia.info ${ }^{5}$

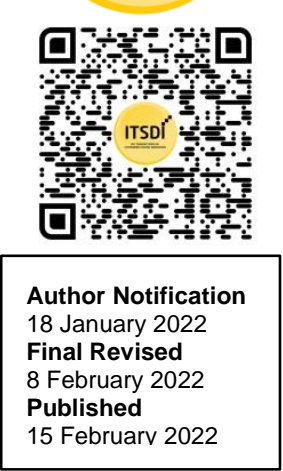

To cite this document:

Rawat, B., Bist, . A. S., Maulani, G., Azizah, N., \& Oganda, F. P. (2022). Research Impact Evaluation Tools: Myths and Reality. IAIC Transactions on Sustainable Digital Innovation (ITSDI), 3(2), 136-142.

Retrieved from https://doi.org/10.34306/itsdi.v3i2.539

DOI: https://doi.org/10.34306/itsdi.v3i2.539

\begin{abstract}
Research is one of the core activities for enhancing existing human capabilities. Research papers, patents, copyright, trademark etc. are used to represent novel ideas and experimental findings. Our aim is to discuss various tools that are used to measure the research impact of researchers among communities. This paper also discusses several critical issues which have emerged due to the malpractice in the academic and research community. Keywords: Google Scholar, ResearchGate, Academia.edu, Scopus, Web of Science

\section{Introduction}

In today's time it is necessary for a researcher to know how much impact is being created by their research work worldwide. Several pieces of information are important to learn about a research such as how many researchers have cited a paper, value of index, ranking documents, weighting the full text of each document, place of publication, name of author and how often and how recently a paper is cited by another scholar. There are many tools being employed to measure the research impact of a researcher [1]. How much impact is being created by a researcher's work is paramount for a researcher to know as it also motivates them to advance in their field and keep doing their work. In this context, many tools exist which can be used to measure the impact of researchers' work. Some of the prominent tools are Google Scholar, ResearchGate, Academia.edu, Scopus, and Web of science, among others. These platforms store researchers' data such as profile information and publication indexed data in a central repository which can be accessed by anyone to meet their research objectives [2].

Other benefits include one can make their research available to people or scientists who are unable to access resources such as someone requiring research paper but cannot access it due to subscription limitation. One can upload their paper and make it available for another scientist to access and download it. Researchers and scientists all around the world are connected to these platforms and can share their ideas and research papers for others to access [3].
\end{abstract}


ResearchGate allows us to organize projects and topics category wise and anyone who wishes to become part of the project or access it can do so collaboratively. Another advantage of this platform is that if one of your colleagues has published a paper in a conference or journal then all the members will be notified about this research publication instantly so they can follow it up. These platforms also allow you to add information about you such as the journal you review for, the societies you are a member of and your experiences, any prize you receive, among others. However, it may be like linkedin does, but it can be utilized to advance research careers. One can discuss research topics by asking questions, one can also discuss with scientists privately without needing their email id [2].

Although these platforms offer numerous advantages to researchers and scientists, it is reported that they are being used inappropriately by some people for enhancing the impact of their predatory journal [4]. Keeping this in mind, in this paper we discuss the various research impact tools and several critical issues that have surfaced in recent time and that need to be addressed in order to motivate researchers to contribute in a meaningful way [5].

\section{Research Question}

RQ1-) Discussing and analyzing various research tools for measuring the research impact.

RQ2-) Discussing critical issues/malpractices happening worldwide in the research community and suggest ways to deal with those issues.

\section{Research Method}

As mentioned in the previous section, there are various platforms to show and manage research impact. These tools are constructive for research output management [6]. The quest of becoming at top in this platform to show supremacy becomes the goal of few researchers. To meet out the goal few researchers do malpractice. As per our analysis we found that one of the common malpractices is to do self-citation. Citation is one of the critical systems to measure impact. Almost all platforms either generate citations or use it to evaluate the significance/impact of research work.

Many scientific communities and academic governing bodies understood it and excluded self-citation for performance measure. Another major way to move up in ranking is number of research documents. Few researchers choose a path of plagiarism that has been strongly banned by all journals and research bodies. Various research papers also have been written on the same issue of plagiarism [7].
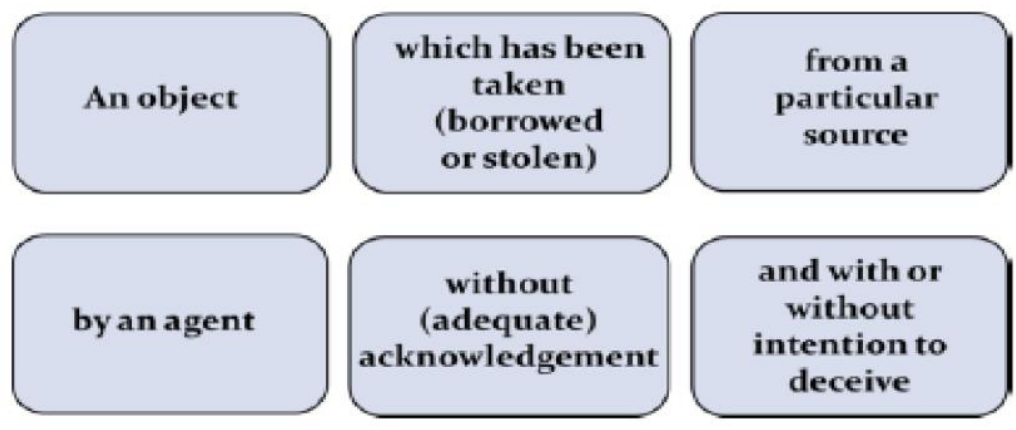

Figure 1. Six elements of Plagiarism

\section{Result and Analysis}

There are various tools available to measure the research impact. Purpose of these platforms is to measure the quality of researchers, institute and country [8]. Also, it adds credibility to the researcher profile that helps in raising research funding. Some of popular tools are listed as follows: 

1. Google Scholar
2. Research Gate
3. Academia.edu
4. Loop
5. Scopus Profile
6. Orchid

\subsection{Google Scholar}

Google is a leading company in the search space. Searching for research papers at one place, maintaining a library of selected papers at one place, scholar citation profile, patent search, sorting of paper with year range, these are important features of Google scholar [9]. Figure2 shows the author's profile that includes number of publications, patents, citation per paper, overall citation, paper title with link, h-index and i10-index [10].

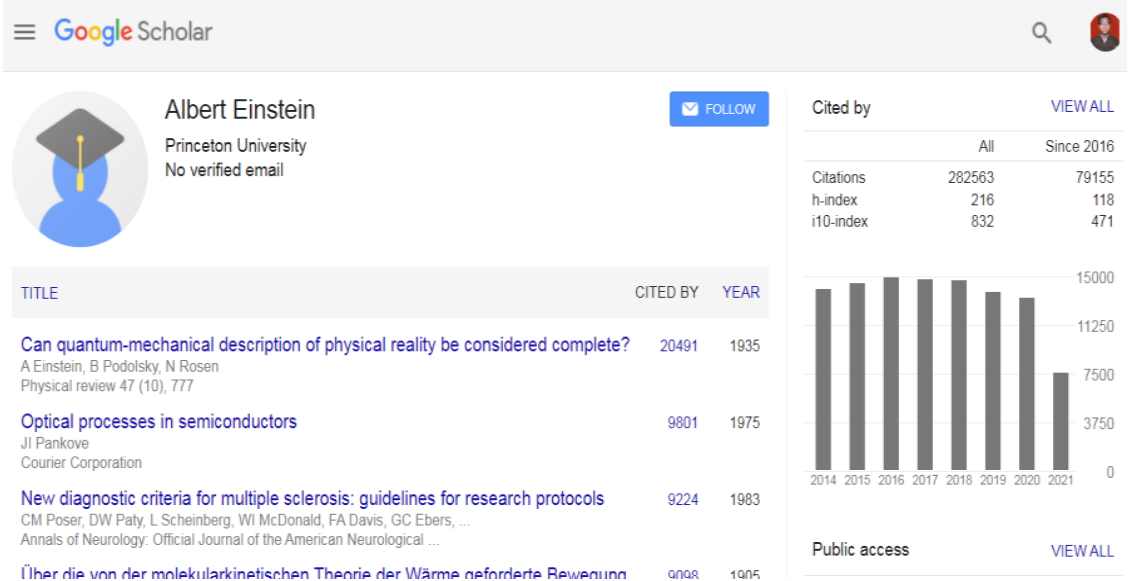

Figure 2. Google scholar Author Profile

\subsection{ResearchGate}

Research is a website where researchers may form a network, ask for papers, share queries. It's like the Facebook of brilliant minds. Just like Google scholar, it also tracks citation, number of views etc. It assigns scores to researchers based on number of views, citation etc. Figure 3. shows the ResearchGate profile [11].

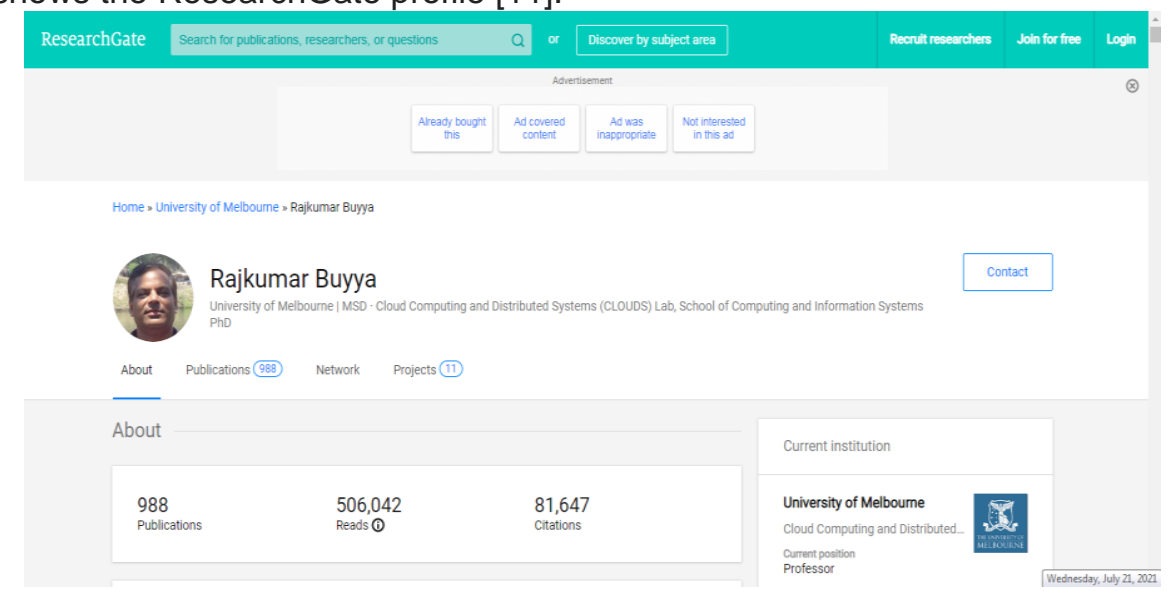

\subsection{Academia.edu}

Figure 3. ResearchGate Author Profile

Academia.edu is a website to upload published and unpublished papers. It provides user dashboard where total papers, number of views, impact and followers can be seen. It's a good platform to manage papers as well as to look at its impact in the community [12]. Figure 4. 
shows the academia author profile [13].

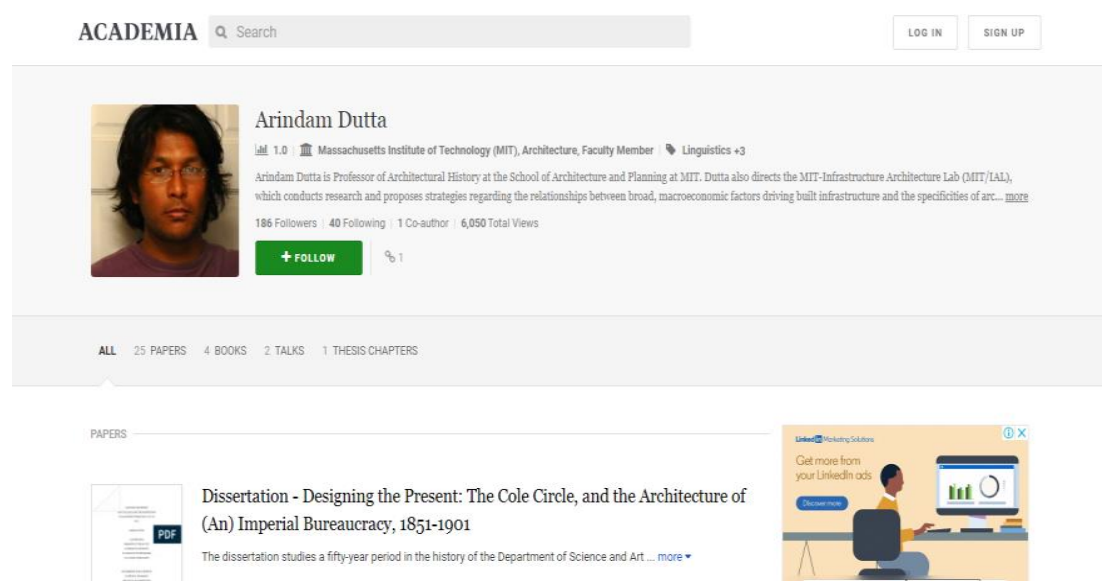

Figure 4. Academia Author Profile

\subsection{Loop}

Among other platform discussed before loop is one of the widely used social network for academicians, researchers and scientist to share their ideas [14], research article and disseminate knowledge. It offers several features including integration, reputation and impact and discovery among others [15]. Its cross-platform integration features make it unique in the sense that author having profile in loop network can make their research articles discoverable across the boundaries of their publishers and organizations. It helps researchers to enhance their article readership and disseminate their work. Another unique feature of loop is that it makes use of advance algorithms which allows researchers to find the most suitable article as per their requirement and helps connect, discuss and collaborate their work with other researchers having similar interest. Overall, this is a very useful platform for researchers to seek, share and generate knowledge [16].

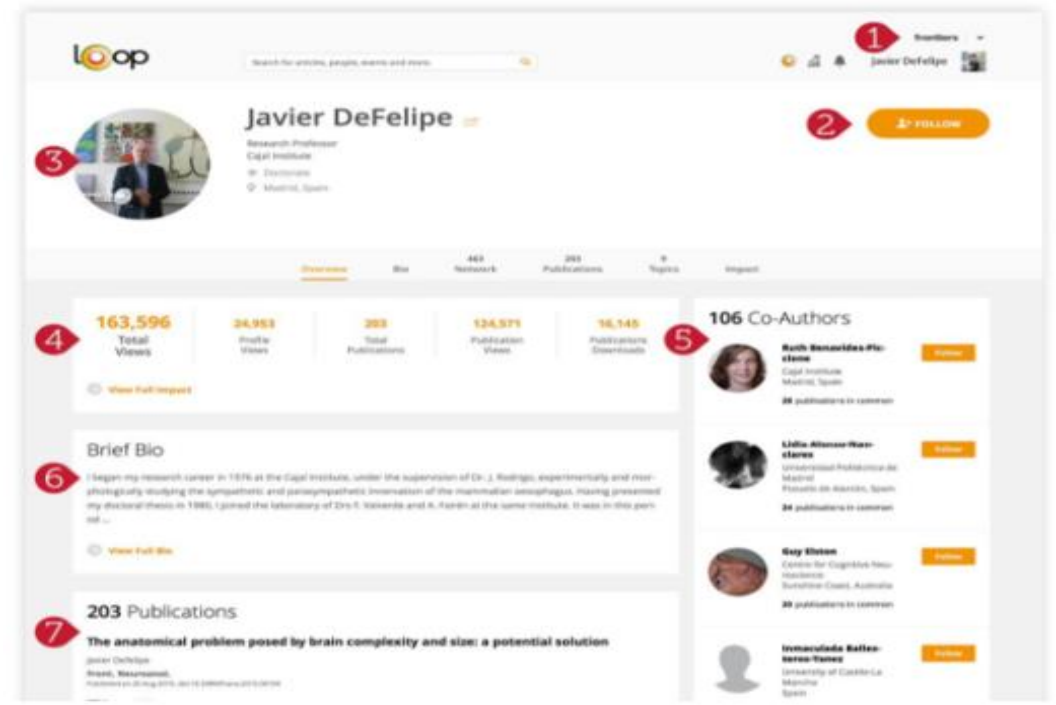

\subsection{Scopus Profile}

Figure 5. Academia Loop Profile

SCOUPS is one of the largest databases containing abstracts and citations of articles being published worldwide [17]. It tracks the articles published in Scopus indexed conference and journal on how many times a paper is cited by authors in their work [18]. There are two major features of this database such as citation analysis and statistics ranking which helps an author, researcher and scientist to track how much impact is created by their research work. 
This is a powerful tool to track, analyze and visualize publications [19]. scopus

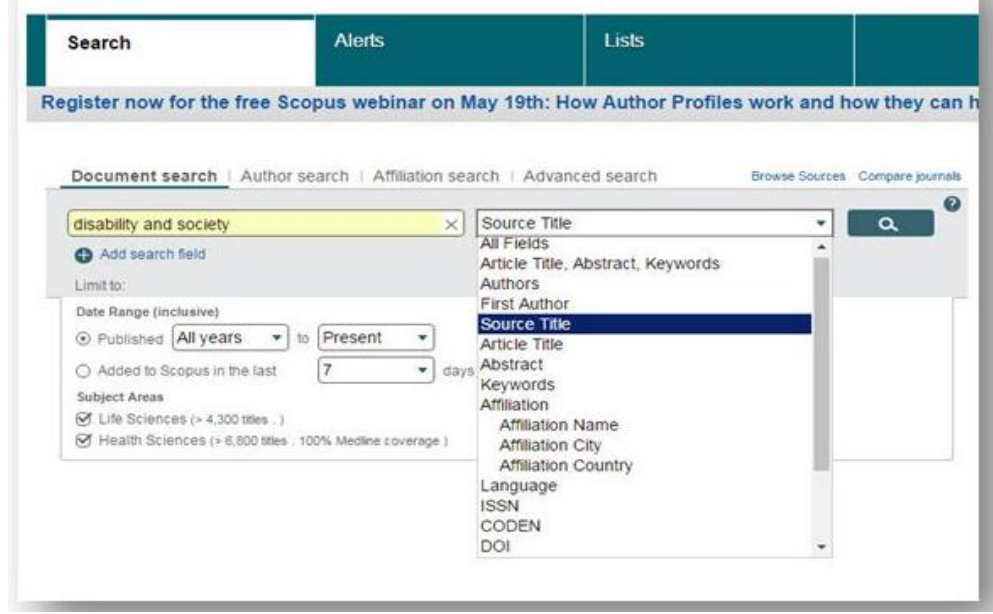

Figure 6. Academia Scopus Profile

In figure6, Scopus document search section is displayed where an author can track its publication by selecting the appropriate options such as source title, as given in the interface [20]. It also allows authors to search their profile with a detailed report which includes detailed author's information such as number of documents an author in Scopus, how many times an author is cited in Scopus, co-authors, subject area, h-index to analyze author's profile [19].

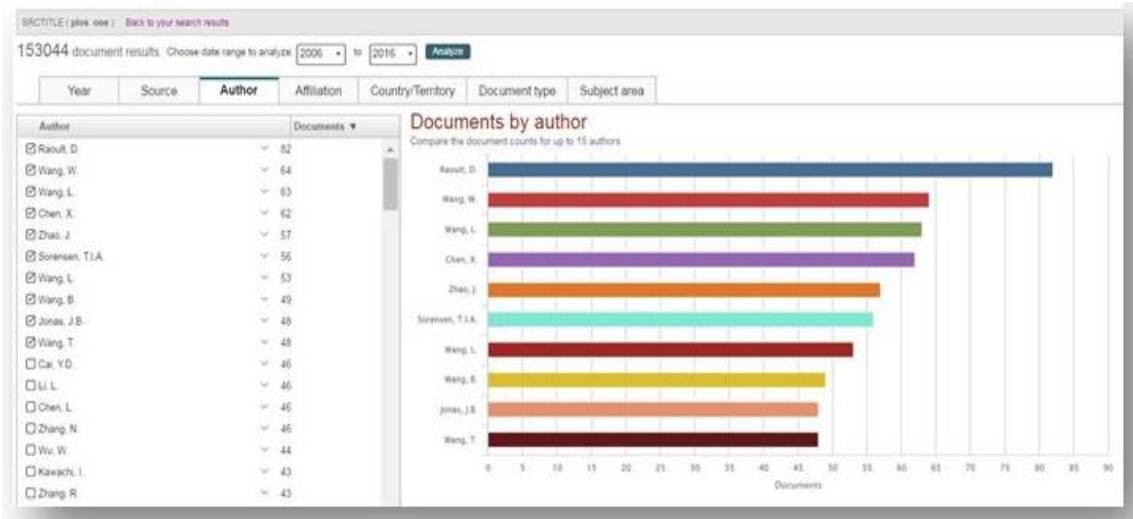

Figure 7. Documents by Author

\subsection{ORCID}

ORCID is one of the widely used open tools and nonprofit organizations which aims to resolve the naming ambiguity and help researchers and scientists to get credit for their valuable contribution in the research area. It works by creating an identifier for researchers and associating it with all the professional and research activities done by researchers such as manuscript and grant submission. Among other benefits it offers the main advantage of registering for ORCID identifier is to allow other researchers to discover your research work and lets a researcher and scholars to register their unique presence irrespective of their name and affiliation history. It is important to note that many bodies such as $\mathrm{NIH}, \mathrm{CDC}$ and AHRQ have made it mandatory to have an ORCID id for researchers about fellowship, research education, career development awards and research training. Moreover, one can add their publications by linking to Scopus. Now it has become possible to distinguish two having the same name through ORCID id. Furthermore, names with variations can also be resolved and researchers who have changed their names during their career can also be identified with the help of ORCID [14]. 


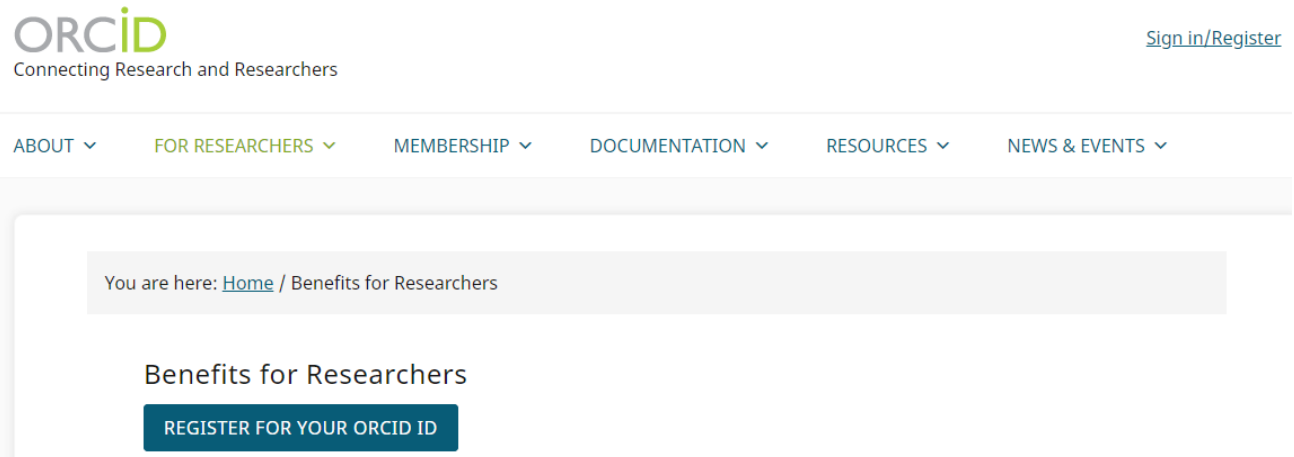

Figure 8. ORCID Profile

\section{Conclusion}

This paper has presented the details of some of the most prominent and widely used platforms which are used to measure the impact of researchers' work such as citation count, no of times an article appeared and helps track, analyze and visualize publications. This paper also discussed malpractices done by some segment of researchers to gain undue benefits out of these platforms. Among all the discussed critical issues self-citation has emerged as malpractice for increasing the citation of researchers. After extensive analysis of existing documents related to this paper, we have found that plagiarism is another menace to move up in the research ranking. We also discussed six elements of plagiarism such as an object, an agent, internet source, without intention to deceive, without acknowledgement among others. Future work will include discussing other parameters which need to be considered such as $\mathrm{H}$ index which can also be manipulated by few researchers. For example, a researcher could cite all his relevant past publications in each paper and some irrelevant one for a good measure and another malpractice would be to publish a paper in different conferences and journals by making few changes in some part of the research work. This helps split citation count between two papers which results in increasing the h-index.

\section{References}

[1] G. Maulani, E. W. Musu, Y. J. W. Soetikno, and S. Aisa, "Education Management using Blockchain as Future Application Innovation," IAIC Trans. Sustain. Digit. Innov., vol. 3, no. 1 , pp. 60-65, 2021.

[2] A. Gregory and J. Leeman, "On the Perception of Plagiarism in Academia: Context and Intent," arXiv Prepr. arXiv2104.00574, 2021.

[3] A. Faturahman, V. Agarwal, and C. Lukita, "Blockchain Technology-The Use Of Cryptocurrencies In Digital Revolution," IAIC Trans. Sustain. Digit. Innov., vol. 3, no. 1, pp. 53-59, 2021.

[4] G. E. Mosha and J. Laizer, "Undergraduate Students' Understanding of Plagiarism," Zambia J. Libr. Inf. Sci. (ZAJLIS), ISSN 2708-2695, vol. 5, no. 1, pp. 21-33, 2021.

[5] E. A. Nabila, S. Santoso, Y. Muhtadi, and B. Tjahjono, "Artificial Intelligence Robots And Revolutionizing Society In Terms Of Technology, Innovation, Work And Power," IAIC Trans. Sustain. Digit. Innov., vol. 3, no. 1, pp. 46-52, 2021.

[6] A. B. Fitra, A. Suharko, F. M. Albar, and D. Apriliasari, "Examination Of Customer Interest In The Use Of The Mandiri Syariah Mobile Application At PT. Bank Syariah Mandiri Bekasi Branch Office," IAIC Trans. Sustain. Digit. Innov., vol. 3, no. 2, pp. 110125, 2022.

[7] B. Cioruța and M. Coman, "Is Plagiarism a Crime or Just a Condemnable Inspiration Method in the Digital World?!," Asian J. Educ. Soc. Stud, vol. 8, no. 3, pp. 27-37, 2020.

[8] U. Rahardja, "Artificial informatics," in 2009 4th IEEE Conference on Industrial Electronics and Applications, 2009, pp. 3064-3067. 
[9] Q. Aini, T. Hariguna, P. O. H. Putra, and U. Rahardja, "Understanding how gamification influences behaviour in education," Int. J. Adv. Trends Comput. Sci. Eng, vol. 8, no. 1.5, pp. 269-274, 2019.

[10] D. Julianingsih, A. G. Prawiyogi, E. Dolan, and D. Apriani, "Utilization of Gadget Technology as a Learning Media," IAIC Trans. Sustain. Digit. Innov., vol. 3, no. 1, pp. 43-45, 2021.

[11] A. Tyler Nix and J. E. Smith, "Research Impact Core: A Research Impact Initiative at the University of Michigan," Med. Ref. Serv. Q., vol. 38, no. 3, pp. 260-270, 2019.

[12] C. R. Sugimoto and V. Larivère, "Benefits and Misuse of Research Impact Indicators: Three New Books on Metrics."

[13] U. Rahardja and E. P. Harahap, "Implementation of Information Planning and Strategies Industrial Technology 4.0 to Improve Business Intelligence Performance on Official Site APTISI," in Journal of Physics: Conference Series, 2019, vol. 1179, no. 1, p. 12111.

[14] Q. Aini, A. Badrianto, F. Budiarty, A. Khoirunisa, and U. Rahardja, "Alleviate fake diploma problem in education using block chain technology," J. Adv. Res. Dyn. Control Syst, vol. 12, no. 2, pp. 1821-1826, 2020.

[15] N. F. Rozy, R. Ramadhiansya, P. A. Sunarya, and U. Rahardja, "Performance Comparison Routing Protocol AODV, DSDV, and AOMDV with Video Streaming in Manet," in 2019 7th International Conference on Cyber and IT Service Management (CITSM), 2019, vol. 7, pp. 1-6.

[16] I. Amsyar, E. Cristhopher, U. Rahardja, N. Lutfiani, and A. Rizky, "Application of Building Workers Services in Facing Industrial Revolution 4.0," Aptisi Trans. Technopreneursh., vol. 3, no. 1, pp. 32-41, 2021.

[17] A. I. L. Wibowo, A. D. Putra, M. S. Dewi, and D. O. Radianto, "Study of Divergence of Go Public Company's Financial Performance Based on Website Before and After Merger Using Window Period Method TIME Frame 2015-2017," Aptisi Trans. Technopreneursh., vol. 1, no. 1, pp. 27-51, 2019.

[18] T. F. Toimah, Y. I. Maulana, and I. Fajar, "Gamification Model Framework and its Use in E-Learning in Higher Education," IAIC Trans. Sustain. Digit. Innov., vol. 3, no. 1, pp. 28-35, 2021.

[19] A. Williams and E. Dolan, "Application of Blockchain Technology in e-LoA Technopreneurship Journal," Aptisi Trans. Technopreneursh., vol. 2, no. 1, pp. 98-103, 2020.

[20] J. Artanti, P. M. Agustini, A. Saptono, G. K. Hanum, and D. O. Regina, "Analysis Of Virtual Product Marketing Strategies To Increase Customer Satisfaction (Case Study On Bukalapak Partners)," IAIC Trans. Sustain. Digit. Innov., vol. 3, no. 2, pp. 86-109, 2022. 